\title{
Investigating a recently discovered biomineralization process in green microalgae
}

\author{
INÉS SEGOVIA CAMPOS, MONTSERRAT FILELLA AND \\ DANIEL ARIZTEGUI
}

University of Geneva

Presenting Author: ines.segoviacampos@unige.ch

Chlorodendrophyceae are a class of green microalgae widespread in aquatic environments. Over the last decade, several species within this class have been found to form intracellular inclusions of amorphous calcium carbonate (ACC), called micropearls, that can be highly enriched in $\mathrm{Sr}$ when this element is available in the environment.

Recent studies suggest considering these microorganisms as potential candidates to develop new bioremediation strategies regarding ${ }^{90} \mathrm{Sr}$ water pollution; however, very little is known about the biomineralization process behind the formation of micropearls, their biological role, and the impact of these microalgae in the geochemical cycle of $\mathrm{Ca}$ and $\mathrm{Sr}$.

The formation process of these intracellular mineral inclusions is currently being studied through laboratory cultures of Tetraselmis chui, T. contracta, and T. marina under controlled conditions. Scanning electron microscopy (SEM) observation of the cultures shows that micropearls are present in the cells throughout the entire cell cycle and are distributed equally among the daughter cells during cell division. In addition, a thin cellular envelope surrounding each ACC inclusion has been observed by transmission electron microscopy (TEM). On the other hand, inductively coupled plasma mass spectrometry (ICPMS) analyses are providing key information about the $\mathrm{Ca}$ and $\mathrm{Sr}$ uptake kinetics of these organisms and their potential impact on the geochemical cycles of $\mathrm{Ca}$ and $\mathrm{Sr}$. We show that the intracellular accumulation of $\mathrm{Ca}$ and $\mathrm{Sr}$ in micropearl-forming species (e.g. T. chui) is, respectively, 50 and 150 times higher than in non-micropearl-forming species (e.g. T. marina), causing a significant decrease in the availability of these elements in the medium. With a view to future bioremediation applications, we also investigate the environmental conditions that promote high $\mathrm{Sr}$ accumulation in micropearls. 